\title{
The Biological Weapons Convention and the biopharmaceutical industry: The views of the United Kingdom
}

\author{
John R. Walker and Tony Phillips
}

Reflecting perhaps the political realities of its time, the Biological and Toxin Weapons Convention (BWC), which entered into force in April 1975, contains no measures-such as inspections or declarations-to ensure compliance. Since the mid 1980 s, however, there have been sustained efforts to strengthen the convention, efforts in which the United Kingdom has played a leading role. The 1991 Gulf War reminded everyone that the risk posed by biological weapons was real and-as UNSCOM's discoveries in Iraq since then have demonstrated all too clearly-not at all exaggerated. The Iraqi experience is one of the reasons the UK believes urgent steps must be taken to strengthen the BWC. Work to that end is now underway.

The BWC's third review conference in September 1991 established an ad hoc group of government experts to examine verification measures from a scientific and technical standpoint. This 2-year exercise concluded that there were various measures that would contribute to strengthening the convention's effectiveness and improving its implementation. The most important of these were declarations and inspections.

Subsequently, a special conference of states parties agreed in September 1994 on a mandate for an ad hoc group (AHG) to consider verification measures and to draft proposals to strengthen the convention. The AHG began its work in Geneva in January 1995 and has made good progress during the 10 sessions since then (the most recent being March 9-13,1998). The AHG is now engaged in detailed negotiations on the "rolling text" of a draft protocol. The current draft contains measures that may have a direct impact on some industrial operations where microorganisms are produced for entirely legitimate purposes, perhaps including some sites in the pharmaceutical industry.

The British Government recognizes that devising effective compliance measures in the biological warfare context poses serious chal-

John R. Walker is principal research officer, Arms Control and Disarmament Research Unit, Foreign and Commonwealth Office, UK. Tony Phillips is technical manager of the Nonproliferation, Chemical and Biological Defense Sector of the Defense Evaluation Research Agency, Porton Down, Salisbury, UK. lenges. Foremost among these is the dual-use problem. Apart from biological weapons themselves, or weapons-filling equipment, there is virtually no piece of equipment, technology, or material that does not have legitimate peaceful uses. Banning particular microorganisms, or prohibiting the use of specified fermenters, is not an option as it would harm valuable, peaceful research, development, and production activities in industry, agriculture, and medicine.

Instead we must find means to improve transparency around the implementation of dual-use technologies. Certainly this means greater openness about activities at relevant facilities. Defining what facilities are "relevant" is one of the challenges the AHG faces. The British government believes these should include biodefense; containment level 4 laboratories; facilities conducting aerobiological studies with microorganisms, facilities working on pathogens or toxins on a list to be specified under the protocol; facilities where there is a particularly high-tech capability (which possibly will be defined as those carrying out genetic modification of these agents), and certain pilot plant production and manufacturing operations possessing well-engineered fermenter assemblies. Such facilities have been misused by some states (not just Iraq) for biological weapons research and development and production.

The UK believes that there must be a limited number of visits to declared sites. Such visits will not only serve to confirm consistency of declarations, but also to further enhance a sense of openness between the parties to the convention, an important regime objective.

Yet we also need to have the possibility of "challenge inspections" in cases of serious suspicions that a given country or site is engaged in activities contrary to the convention. These elements-greater transparency through declarations and visits-are at the heart of the regime we are trying to construct in Geneva. The UK is convinced that these measures will put us in a much better position to deter and, if necessary, deal with the proliferation of biological weapons.

The UK recognizes that a meaningful BWC protocol will inevitably impinge on the pharmaceutical and biotechnology industries. We understand that industry would rather not have to fill out additional declarations or be potentially subject to visits or inspections. No industry likes additional regulatory requirements, but we believe that a worthwhile protocol that will improve the BWC's effectiveness without imposing an unreasonable burden can be designed. The UK has pioneered practical work with industry on the conduct of on-site activities at commercially sensitive sites (research and manufacturing) to see whether sufficient access can be given to inspectors to enable them to do their job, while ensuring that commercial proprietary information can be protected and that the administrative and resource burden is kept to a minimum. The evidence from eight mock inspection and visit exercises is that these objectives can be met.

Since 1993 there have been close consultations between government and industry in the UK on BWC issues. Officials from the Foreign and Commonwealth Office, Ministry of Defense, and the Department of Trade and Industry have worked closely with the Association of the British Pharmaceutical Industry and individual companies. We have also had discussions with the Pharmaceutical Research and Manufacturers of America. This collaboration has been exceptionally valuable. Advice from industry, as well as a clear appreciation of industry's concerns, have helped shape the UK's approach to the negotiations. This cooperation was in evidence last November when government officials were able to conduct a practice visit at a large pharmaceutical research facility, and shortly afterward a government-industry seminar was held in the Foreign and Commonwealth Office. We shall ensure that such cooperation continues.

To conclude, the British government firmly believes that steps must be taken to strengthen the BWC given the present risks posed by biological weapons. If we are to secure measures that will give us greater access to facilities in countries of concern, we must be prepared to commit our own sitesboth government and private-to the same measures. With academia and industry to advise us about the technical issues, we are in a good position to aim for a sound balance, securing measures that are sufficiently broad and stringent to provide real assurance of compliance and deterrence of would-be proliferators, without overburdening industry, damaging its competitiveness, or threatening commercial proprietary information. III 